\title{
Demonstration of pathogenic bacteria in "sterile" inflammatory exudates
}

\author{
RC BRIDGER
}

From the Department of Microbiology, Godfrey Pathology Laboratory, 137 Kilmore Street, Christchurch 1, New Zealand

SUMMARY One hundred and twenty-seven exudates from inflammatory processes, judged sterile ${ }_{\dot{\omega}}$ after incubation on standard isolation media, were further investigated. This involved the exclusion of slow-growing strains by a further 48 hours incubation of the primary plates and subcultures from hypertonic broth that had been inoculated concurrently with the initial cultures.

Over $80 \%$ of otherwise sterile exudates grew presumptive pathogens only after passage $\stackrel{\circ}{工}$ through the hypertonic broth and no further isolations resulted from extended incubation of the primary cultures.

A history of current, or recent, antibiotic therapy commonly accompanied the demonstration of these aberrant strains and clinical remission of symptoms usually followed fresh antibiotic $\underset{\omega}{\infty}$ therapy directed solely against the revertant isolates.

The absence of growth of pathogenic organisms on standard media in exudates from non-draining inflammatory lesions is a not uncommon laboratory dilemma. The incidence is significant and steady but because it constitutes a negative finding, figures are seldom reported. An extended period of morbidity in the patient is, however, a general consequence of this type of microbiological failure. Following the successful demonstration of pathogens in a series of apparently sterile nasal sinus exudates, ${ }^{1}$ similar methods were applied to all "sterile" exudates processed in the Microbiology Department over a twoyear period and a marked increase in the isolation rate of pathogens resulted.

\section{Material and methods}

CLINICAL MATERIAL

Clinical material fell broadly into three classes: (i) from localised acute lesions of soft tissue (216); (ii) from infected joints (172); and (iii) from nasal sinus exudates (189). Of those showing significant pus but no growth on primary isolation media, $34(16 \%)$ soft tissue, $25(15 \%)$ joint fluid and $68(36 \%)$ nasal sinus specimens qualified for hypertonic broth passage (see Table 1). All material was aspirated and received either as fluid or as pus in syringes. Nasal sinus specimens were taken either as middle meatal aspirates, ${ }^{1}$ antral washes or as antral pus by direct puncture of the sinus cavity. Samples received on $\stackrel{2}{\circ}$ swabs were excluded from the series because the $\stackrel{\AA}{\varrho}$ risk of contamination by commensal flora with this $\overrightarrow{\overrightarrow{0}}$ type of collection was felt to be unacceptably high. 3

\section{GRAM STAINS}

These were carried out on smears either from swung deposits of joint aspirates or directly from pus.

Table 1 Sources and numbers of exudates requiring hypertonic broth reversion to demonstrate a pathogen

\begin{tabular}{|c|c|}
\hline Source & Number \\
\hline Synovial fluid & 25 \\
\hline Breast abscess & 10 \\
\hline Peritoneal fluid & \\
\hline (postop and post-dialysis) & 7 \\
\hline $\begin{array}{l}\text { Postop joint lesions } \\
\text { Ischiorectal abscess }\end{array}$ & $\begin{array}{l}4 \\
3\end{array}$ \\
\hline Middle ear abscess & 2 \\
\hline Parotid gland infection & 2 \\
\hline Abscess face & 1 \\
\hline Abscess thigh & 1 \\
\hline Infected pharyngeal cyst & 1 \\
\hline Postop invertebral disc infection & 1 \\
\hline Abscess axilla & 1 \\
\hline Fluctuant mass, back & 1 \\
\hline Nasal sinusitis & \\
\hline Middle meatal aspirate & 32 \\
\hline Antral wash & 17 \\
\hline Antral puncture & 19 \\
\hline Total & 127 \\
\hline
\end{tabular}




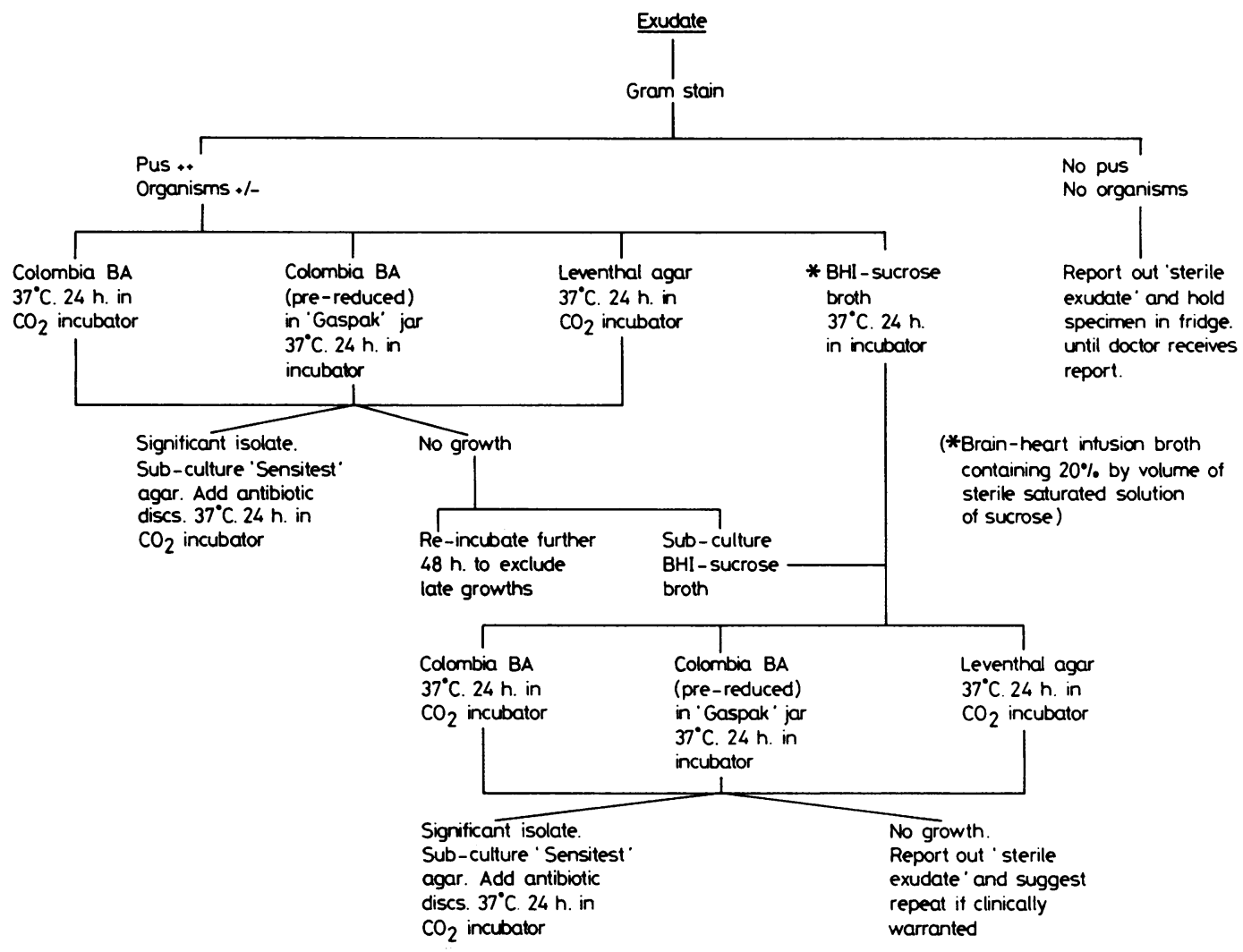

Method of isolation of bacterial pathogens from all exudates.

\section{METHODS}

Bacteriological investigation was performed as shown in the Figure. The identity of Gram-negative organisms was confirmed by passage through API$20 \mathrm{E}$ and those Gram-positive isolates requiring further identification were treated according to the methods outlined in Cowan and Steel. ${ }^{2}$ The inclusion of Levanthal medium to select for Haemophilus infuenzae was directed not only at nasal sinus exudates but also at possible strains of this organism causing suppurative arthritis. ${ }^{3}$

The single case of Mycobacterium tuberculosis infection was treated differently from all other exudates for clinical reasons. The lesion was fluctuant, indolent, of several months duration and as the patient had been previously diagnosed and treated for pulmonary tuberculosis, it was decided to culture on to Löwenstein-Jensen medium as well as the standard regimen used for the series.

\section{ANTIBIOTIC SENSITIVITY TESTING}

Sensitivity testing of isolates was carried out by standard disc diffusion with inhibition zones meas- ured against a disc template based on subculture of commercial quality control strains of organisms. The antibiotics of common choice were: penicillin, ampicillin, erythromycin, tetracycline and cotrimoxazole. Additional antibiotics were tested as required and strains of Staphylococcus aureus resistant to standard penicillins were tested against methicillin. All strains of $H$ infuenzae were tested for betalactamase production by "Oxoid" beta-lactamase test papers and antibiotic testing of this species was carried out on Levanthal agar.

\section{Results}

\section{GRAM STAINS}

Where broth reversion was required, characteristic parent-form bacteria were rare in Gram films of primary exudates. Where structures were present, their morphology was generally pleomorphic and their reaction Gram-negative, irrespective of genera. Seventy-three films $(58 \%)$ showed such structures and the remaining $54(42 \%)$ showed no recognisable structures (see Discussion). 
Table 2 Isolates and numbers of pathogens after hypertonic reversion from soft tissues and joints

\begin{tabular}{lc}
\hline Isolate & Number \\
\hline Staph aureus & 29 \\
Strep non-haem & 6 \\
Peptostreptococcus spp & 4 \\
Micrococcus spp & 3 \\
Strep faecalis & 3 \\
Acinetobacter spp & 2 \\
S citreus & 1 \\
Myco tuberculosis* & 1 \\
Total & 49 \\
No growth & 10 \\
\hline
\end{tabular}

*Grown only on Löwenstein-Jensen medium.

Table 3 Isolates and numbers of pathogens after hypertonic reversion from nasal sinus exudates

\begin{tabular}{lc}
\hline Isolate & Number \\
\hline Staph aureus & 25 \\
H influenzae & 10 \\
Strep pneumoniae & 5 \\
B-haem Strep group A & 5 \\
Strep non-haem & 4 \\
Pseudomonas spp & 4 \\
Peptostreptococcus spp & 3 \\
Klebsiella spp & 2 \\
H parainfluenzae & 2 \\
Total & 60 \\
No growth & 8 \\
\hline
\end{tabular}

\section{ISOLATES}

The identity and percentage of each revertant species from soft tissues and joints is shown in Table 2 and those from nasal sinuses in Table 3. Revertants of $H$ influenzae were restricted to nasal sinus exudates and only two strains of this species were found to be beta-lactamase producers. Of the 54 revertant Staph aureus isolates, none was sensitive to natural penicillins and two were methicillinresistant.

\section{Discussion}

The role of cell wall-damaged strains of bacteria as pathogens has been in contention for many years. ${ }^{4-12}$ The barrier to their universal acceptance in this role has been the lack of clear definitions of the degrees of wall damage and, more importantly, whether such strains revert, replicate and produce toxins in vivo. Recently published work, however, supports their ability to sustain established infections. ${ }^{13-17}$

The fact that some strains return to parent form after a single passage through hypertonic broth is not in doubt. This type of revertant organism conforms to the description of "unclassified walldefective variants" as defined by McGee et al ${ }^{18}$ in that they yield vegetative parent bacteria after first passage through hypertonic media but do not grow in the same media without initial osmotic supplement. It was this type of organism investigated in the study reported here.

Although these aberrant forms were not invariably demonstrable by Gram staining of the initialo exudates in this series, it should be noted that this does not exclude their presence. ${ }^{19}$ Conversely, Gram stains of positive hypertonic broth cultures alwayses showed some individual organisms that were aber- $\overrightarrow{0}$ rant in morphology and many that were Gramvariable in reaction but all reverted to parent formw and correct Gram reaction at first subculture onto standard solid medium.

The effects of suboptimal doses of antibiotics on bacteria is well documented ${ }^{20-24}$ and the reduced effect even of full doses in a sealed infection alsour seems proven. Reasons for the latter include: $\mathrm{pH}_{\circ}$ changes in such an environment may produce $\mathrm{a}_{-}$ marked shift to the alkaline side with a consequent reduction in antibiotic activity of some antibacteria? agents ${ }^{25}$; the fact that some antibiotics fail to reach therapeutic levels in a sealed lesion ${ }^{26}$ and a reduc $-\infty$ tion in the rate of bacterial division may result from the steady loss of trapped bacterial nutrients thus rendering antibiotics ineffectual because onlys actively dividing organisms are vulnerable to antibiotic action. There are then, a range of antibiotico effects known to alter bacteria morphologically and $\mathbb{B}$ metabolically, all of which do not necessarily steril $-\overrightarrow{\vec{\theta}}$ ise lesions.

In this series only 17 of the 127 investigated hade not been treated with antibiotics for their infection? Of this 17 , five had received therapy for unrelate infections during the previous three months and the remainder denied any therapy during the previous year. However, eight of the latter group failed to produce growths in hypertonic medium. The rela- -3 tion between antibiotic challenge and aberrant bac-o teria would seem very close in this study.

The antibiotic sensitivity patterns of isolates wer significant. Strains sensitive to all five drugs of choice comprised only $9 \%$ of the total. Resistance tom two agents out of five accounted for $35 \%$; to threen agents out of five, $24 \%$ of isolates; to four agents oun of five, $26 \%$ of isolates and to all five agents, $6 \%$ of the whole series. These generally increased resis tance figures would seem to reflect the antibiotic stress to which revertant isolates had been sub $\mathbb{D}$ jected. They would also support the suggestion of Palmer $^{27}$ that where multiresistant aberrant strains are present in an infection, any completion or dis- $-\overrightarrow{\mathbb{D}}$ continuation of therapy allows the re-emergence of that strain in its pathogenic parent form. If this pre mise is accepted, an extension of the primary infec? tious process would seem axiomatic. 
The ratios of Gram-positive to Gram-negative isolates were noteworthy. The figure of $15 \cdot 5: 1 \cdot 0$ in the soft tissue-joint categories supported the thesis that the generally preferred penicillin group antibiotics may not be adequate to sterilise all enclosed lesions. The nasal sinus category with a ratio of $1 \cdot 6: 1 \cdot 0$ presumably reflects the greater accessibility of this area, through an open ostium during periods of drainage, to changing opportunist flora. Any succeeding exacerbation of infection that closes the ostium by oedema would, of course, produce the same barriers to successful treatment faced by the permanently sealed lesions of soft tissues and joints.

The particularly high incidence of Staph aureus in all categories appears to demonstrate the ubiquitous nature of this species, its proven ability to act either as a commensal or a pathogen, the ease of expression of its genetic determinant for beta-lactamase production and the problems of its eradication, even with sensitive strains, by suboptimal amounts of antibiotic directed against its cell wall. A corollary to this concerns the ratios of exudates requiring broth conversion in each category. Two-and-a-half as many hypertonic cultures were needed for sinus exudates as for exudates from other sites. This disparity presumably arises from the multiple treatments required for the type of chronic disease present in nasal sinuses and the consequently greater opportunity for the emergence of cell wall-damaged forms.

The results of therapy directed against revertant pathogens led to an adequate resolution of lesions in $86 \%$ of the soft tissue-joints groups. The other $14 \%$ were unable to be confirmed due to referral back from specialists to general practitioners. In the nasal sinus group, satisfactory remissions were achieved in $71 \%$ of treated patients. The $21 \%$ failure rate was due to a variety of reasons and these included: lack of patient compliance with dosage schedules; too short a course of therapy and the decision by some practitioners not to use the antibiotic advised in the laboratory report.

Although it can be argued that adequate drainage of lesions is superior to chemotherapy, this presumes easy accessibility to the lesion for surgical intervention; a completely unimpaired immune response in the patient and also implies an extended period of convalescence.

Given unequivocal signs of an acute inflammatory process, including the presence of significant pus, determined efforts to demonstrate an infective cause should be pursued. It would appear that an initial inability to grow a pathogen does not exclude its presence and that any method likely to increase the yield of organisms should be routinely undertaken. The inoculation of a tube of hypertonic broth with exudates from any patients showing inadequate response to therapy is a simple and inexpensive addition to the laboratory profile. In the light of the results of this investigation such an approach would seem obligatory, both from a microbiological and a clinical point of view.

I am grateful to Miss Anne Grigor and her staff for technical assistance.

\section{References}

' Bridger RC. Sinusitis: an improved regime of investigation for the clinical laboratory. J Clin Pathol 1980;33:276-81.

2 Cowan ST, Steel KJ. Manual for the identification of medical bacteria. 2nd ed. Cambridge: Cambridge University Press, 1974.

${ }^{3}$ Leek JC, Robbins DL. $H$ inftuenzae tenosynovitis. Ann Rheum Dis 1980;33:530-3.

${ }^{4}$ Godzeski CW, Brier G, Griffith RS, Black UR. Association of bacterial L-phase organisms in chronic infections (Letter). Nature 1968;205:1340.

${ }^{5}$ Charache P. Atypical bacterial forms in human disease. In: Guze LB, ed. Microbial protoplasts, spheroplasts and L-forms. Baltimore: Williams \& Wilkins, 1968:484-94.

- Barile MF. Variant bacteria and chronic disease. Hosp Pract 1968;3:41-3.

' Finegold DS. Biology and pathogenicity of microbial spheroplasts and L-forms. N Engl J Med 1969;281:1159-70.

${ }^{8}$ Charache $\mathrm{P}$. Cell wall-defective bacterial variants in human disease. Ann N Y Acad Sci 1970;174:903-11.

${ }^{9}$ Louria DB. L-forms, spheroplasts and aberrant forms in chronic sepsis. Adv Intern Med 1971;17:125-42.

${ }^{10}$ Guinan PD, Neter E, Murphy GP. The significance of L-forms in human renal disease. $J$ Urol 1972;108:50-3.

"Watanakunakorn C, Glotzbecker C. In vivo behaviour of revertants from Staphylococcus aureus L-phase variants compared with the parent strain. Infect Immun 1975;11:1182-6.

12 Watanakunakorn C. Are cell wall-defective microbial variants important in clinical infectious diseases? J Antimicrob Chemother 1979;5:239-41.

${ }^{13}$ Bakir M, Attia H, Gad W. L-forms of Staphylococcus aureus as a cause of resistant conjunctivitis. Bull Ophthalmol Soc Egypt 1978;71:237-45.

${ }^{14}$ Grekova NA, Tolmacheva TA, Verschilova PA. On the pathogenicity of non-stable Brucella L-forms and their revertants. J Hyg Epidemiol Microbiol Immunol (Praha) 1979;23:129-34.

${ }^{15}$ Gusman BS, Vulfovitch IuV, Kagan GIa. Morphogenesis of the heart lesion in experimental infection with Streptococcal L-forms. Arkh Patol 1980;42:26-32.

${ }^{10}$ Salobi RIu, Berezovski'i BA, Golanov VS. Significance of mycobacterial L-forms in the development of pulmonary tuberculosis relapses. Vrach Delo 1981; Dec(12):77-80.

${ }^{17}$ Mavrov II. Isolation of gonococcal L-forms from patients and their role in the pathology of gonococcal infection. Vestn Dermatol Venerol 1981;2:22-7.

18 McGee ZA, Wittler RG, Gooder H, Charache P. Wall-defective microbial variants: terminology and experimental design. $J$ Infect Dis 1971;123:433-8.

19 Cate TR. Cell wall-defective bacteria. In: Lenette EH, Spaulding EH, Truant JP, eds. Manual of clinical microbiology. 2nd ed. Washington DC: American Society for Microbiology, 1974:338-43.

${ }^{20}$ Klainer AS, Perkins RL. Normal and abnormal morphology of micro-organisms. JAMA 1971;215:1655-7. 
"Lorian V, Atkinson B. Abnormal forms of bacteria produced by antibiotics. Am J Clin Pathol 1975;64:678-88.

${ }^{22}$ Lorian V. Abnormal forms of bacteria. Mt Sinai J Med 1976;43:762-75

${ }^{23}$ Washington JA II. The effects and significance of subminimal inhibitory concentrations of antibiotics. Rev Infect Dis 1979;1(5):781-6.

${ }^{24}$ Lorian V, Waluschka A, Kim Y. Abnormal morphology of bacteria in the sputa of patients treated with antibiotics. J Clin Microbiol 1982;16:382-6.

${ }^{25}$ Carenfelt C, Eneroth CM, Lunberg C, Wretlind B. Evaluation of the antibiotic effect of treatment of maxilliary sinusitis. Scand J Infect Dis 1975;7:259-64.
${ }^{20}$ Lundberg C, Malmborg AS, Ivemark BL. Antibiotic concentrations in relation to the structural changes in maxillary sinus mucosa following intramuscular or peroral treatment. Scand $J$ Infect Dis 1974;6:187-91.

${ }^{27}$ Palmer DW. Inadequate response to "adequate" treatment of bacterial infection: L-forms and "bactericidal" antibiotic activ- $\tau$ ity. J Infect Dis 1979;130:725-7.

Requests for reprints to: RC Bridger, Pathology Laboratory, Colston House, 137 Kilmore Street, Christchurch 1, New Zealand. 